\title{
PERUBAHAN STANDAR DESAIN JALAN TAMBANG BOBOKA SITE TANJUNG BULI BERDASARKAN KAJIAN GEOTEKNIK UNTUK MENGURANGI MATERIAL MOVEMENT DAN MEMPERCEPAT DEVELOPMENT JALAN TAMBANG
}

\author{
Zulpryadi Mubarak ${ }^{1}$, Eko Aditya ${ }^{2}$, Dr. Ir. Barlian Dwinagara, MT $^{3}$ \\ ${ }^{1}$ Pakal Mine Production Assistant Manager, PT Antam Tbk, UBP Nikel Maluku Utara \\ ${ }^{2}$ Quality Management Assurance Manager, PT Antam Tbk, UBP Nikel Maluku Utara \\ ${ }^{3}$ Coordinator of Graduate Program, Mining Engineering Department, UPN “Veteran” Yogyakarta
}

\begin{abstract}
ABSTRAK
Pada bulan Januari tahun 2018 PT. Antam Tbk UBP Nikel Maluku Utara, site Tanjung Buli, harus melanjutkan development jalan produksi yang bernama jalan tambang Boboka. Jalan tambang Boboka harus digunakan sebagai jalan produksi pada bulan Juli tahun 2018 agar produksi site Tanjung Buli tetap terjaga. Setelah dilakukan desain berdasarkan standar parameter jalan tambang dan dilakukan estimasi waktu development-nya, jalan tambang Boboka diperkirakan selesai diakhir bulan Agustus 2018. Untuk itu harus dilakukan percepatan pembuatan jalan tambang Boboka.
\end{abstract}

Setelah dilakukan penelitian geoteknik, diketahui bahwa perubahan yang dapat dilakukan untuk standar parameter jalan tambang Boboka adalah dengan menambah tinggi jenjang, lebar berm dan sudut lereng keseluruhan. Perubahannya adalah, tinggi jenjang dari 6 meter menjadi 20 meter, lebar berm dari 3 meter menjadi 5 meter dan sudut lereng keseluruhan dari $45^{\circ}$ menjadi $55^{\circ}$. Untuk sudut kemiringan lereng tunggal tidak ada perubahan yaitu $60^{\circ}$. Dari perubahan tersebut diperoleh kenaikan nilai FK dari 1,30 menjadi 1,65. Perubahan standar parameter tersebut membuat moving material dari development jalan tambang Boboka berkurang secara signifikan sehingga waktu development jalan tambang Boboka dapat dipercepat. Selain itu, dengan berkurangnya moving material development jalan tambang Boboka, PT Antam Tbk UBP Nikel Maluku Utara dapat melakukan efisiensi.

Kata kunci: jalan tambang, penelitian geoteknik, moving material.

\begin{abstract}
In January 2018 PT. Antam Tbk UBP Nickel North Maluku, Tanjung Buli site, must continue the development of a production road called the Boboka mining road. The Boboka mine road must be used as a production road in July 2018 so that the production of the Tanjung Buli site is maintained. After the design is based on the standard mining road parameters and estimated development time, the Boboka mine road is estimated to be completed by the end of August 2018. For this reason, acceleration of the construction of the Boboka mine road must be made.

After conducting geotechnical research, it is known that changes that can be made to the standard parameters of the Boboka mine road are adding height, berm width and overall slope angle. The changes are, the height of the level from 6 meters to 20 meters, berm width from 3 meters to 5 meters and the overall slope angle from $45^{\circ}$ to $55^{\circ}$. For a single slope angle there is no change that is $60^{\circ}$. From these changes an increase in FK values was obtained from 1,30 to 1,65. The change in standard parameters made the moving material from the development of the Boboka mine road significantly reduced so that the development time of the Boboka mine road could be accelerated. In addition, with the reduction in moving material development of the Boboka mine road, PT Antam Tbk UBP Nickel North Maluku can improve efficiency.
\end{abstract}

Keywords: mining road, geotechnical research, moving material. 


\section{A. PENDAHULUAN}

\section{A.1 Latar Belakang}

PT Antam Tbk Unit Bisnis Pertambangan Nikel Maluku Utara (PT Antam UBPN Malut) melakukan penambangan dengan sistem tambang terbuka yaitu open cast. Dalam sistem tambang terbuka, salah satu bagian yang terpenting adalah jalan tambang. Jalan tambang adalah jalan yang berada di site tambang yang berfungsi sebagai penghubung lokasi-lokasi penting, antara lain lokasi tambang dengan stock yard, grizzly, kantor dan tempat-tempat lain di wilayah penambangan.

Dikarenakan pentingnya jalan tambang, desain jalan tambang harus dilakukan dengan baik. Kesalahan desain jalan tambang dapat berakibat tidak layaknya jalan untuk digunakan, tidak aman (unsafety), tingginya biaya development jalan tambang serta dapat berpotensi menghentikan proses penambangan.

Tantangan yang diperoleh pada desain jalan tambang Boboka adalah bagaimana cara membuat desain jalan tambang yang baik sehingga dapan mempercepat development serta tetap mengedapankan safety dan efisiensi. Sehingga dari tantangan ini diperlukan suatu ide atau perubahan pada desain jalan tambang Boboka.

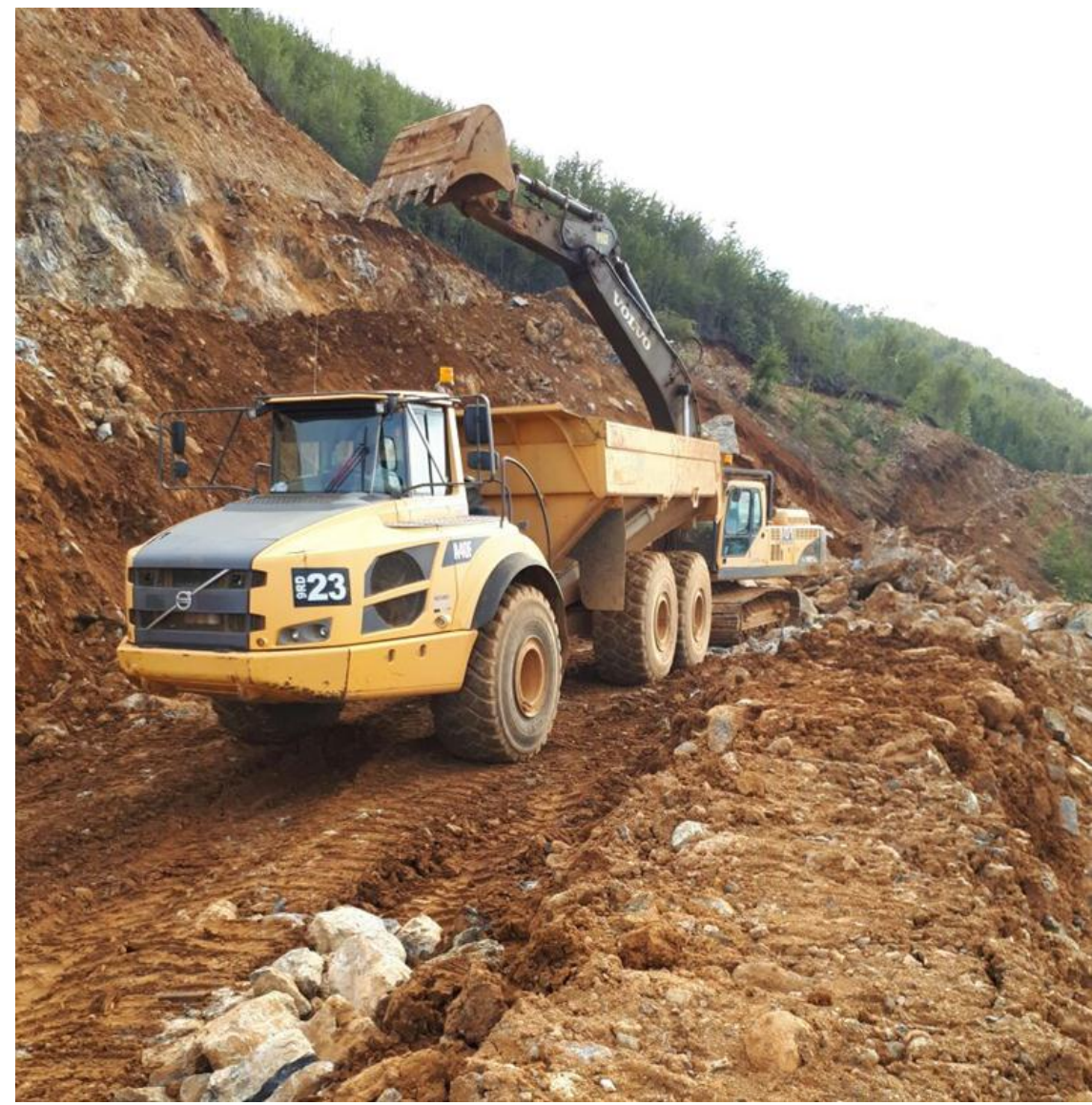

Gambar 1. Proses Development Jalan Tambang.

\section{A.2 Tujuan}

Berikut tujuan dari penelitian ini, yaitu:

- $\quad$ Mempercepat waktu development jalan tambang Boboka

- Mengurangi jumlah moving material

- $\quad$ Efisiensi biaya dari berkurangnya material movement

- Membuat standar baru desain jalan tambang Boboka 


\section{A.3. Pendekatan Pemecahan Masalah}

Sebelum memutuskan untuk melakukan perubahan standar desain jalan tambang Boboka site tanjung buli berdasarkan kajian geoteknik. Dilakukan beberapa pendekatan pemecahan masalah untuk development dan memetakan untung ruginya, sebagai berikut

Tabel 1. Pendekatan Pemecahan Masalah.

\begin{tabular}{|c|c|c|c|}
\hline No & Pendekatan Pemecahan Masalah & Keuntungan & Kerugian \\
\hline 1 & $\begin{array}{l}\text { Mendesain dengan cara menggeser posisi } \\
\text { jalan sehingga sebagian jalan merupakan } \\
\text { material timbunan }\end{array}$ & $\begin{array}{l}\text { - Material movement lebih } \\
\text { sedikit } \\
\text { - Jalan yang sudah terbentuk } \\
\text { masih bisa digunakan }\end{array}$ & $\begin{array}{l}\text { - Rawan terjadi } \\
\text { longsor } \\
\text { - Rawan terjadi } \\
\text { kecelakaan } \\
\text { lingkungan }\end{array}$ \\
\hline 2 & $\begin{array}{l}\text { Mendesain jalan alternatif melalui lokasi } \\
\text { bawah Boboka }\end{array}$ & $\begin{array}{l}\text { - Material movement banyak } \\
\text { - Area di bawah Boboka bisa } \\
\text { menjadi dermaga baru }\end{array}$ & $\begin{array}{l}\text { - Grade kemiringan } \\
\text { jalan tinggi } \\
\text { - Membutuhkan } \\
\text { izin baru untuk } \\
\text { membuat } \\
\text { tambahan } \\
\text { dermaga }\end{array}$ \\
\hline 3 & $\begin{array}{l}\text { Membuat desain baru dilokasi yang sama } \\
\text { dengan merubah standar parameter } \\
\text { geometri jalan tambang }\end{array}$ & $\begin{array}{l}\text { - Material movement lebih } \\
\text { sedikit } \\
\text { - Jalan yang sudah terbentuk } \\
\text { masih bisa digunakan } \\
\text { - Tidak rawan longsor } \\
\text { - Debit air limpasan lebih } \\
\text { sedikit }\end{array}$ & $\begin{array}{l}\text { - Harus melakukan } \\
\text { kajian geoteknik }\end{array}$ \\
\hline
\end{tabular}

\section{B. METODOLOGI PENELITIAN}

Metodologi penelitian yang dilakukan adalah metode kuantitatif, dimana untuk memecahkan masalah perubahan standar jalan tambang Boboka dilakukan kajian geoteknik. Hasil dari kajian tersebut berupa rekomendasi teknis terhadap lereng jalan tambang. Dari rekomendasi tersebut, selanjutnya dibuatkan simulasi desain jalan tambang dengan berbagai macam variasi sudut dan ketinggian bench untuk diuji slope stability-nya.

\section{HASIL DAN PEMBAHASAN}

Penelitian perubahan standar desain jalan tambang Boboka site tanjung buli dimulai pada Desember 2017 - Maret 2018. Seperti yang disebutkan diatas bahwa tujuan utama dari penelitian ini adalah mengurangi moving material sehingga development jalan tambang dapat dilakukan lebih cepat dan efisien.

\section{C.1. Kajian Geoteknik}

Kajian geoteknik dilakukan pada bulan Desember 2017 - Januari 2018. Tujuannya adalah untuk memberikan kajian, analisa dan rekomendasi geoteknik pada area jalan tambang Boboka. Dalam kajian geoteknik tersebut, dilakukan pengukuran orientasi bidang kekar dalam bentuk kemiringan (dip) dan arah kemiringan (dip direction).

Menurut Hoek and Bray (1981), kestabilan lereng dapat dianalisis sesuai jenis kelongsoran yang direpresentasikan dalam bentuk bidang gelincir. Dengan menggunakan software stereonet 10, diketahui bahwa jenis longsoran yang berpotensi terjadi dilereng jalan tambang Boboka adalah longsoran baji dan longsoran bidang. 
Selain itu, dilakukan juga pengambilan sampel bongkah untuk dilakukan pengujian sifat fisik dan kuat tekan uniaksial. Hasilnya, material penyusun lereng jalan tambang Boboka merupakan material bedrock yang termasuk dalam klasifikasi material low strength dan moderate dengan nilai kuat tekan uniaksial 36,55 MPa. Hasil tersebut kemudian digunakan sebagai input data analisa kestabilan lereng. Dengan menggunakan software Phase2 V8.0 dari Rocscience, perhitungan kestabilan lereng tunggal (individual slope) dan lereng keseluruhan (overall slope) dilakukan. Kriteria lereng dalam keadaan stabil jika nilai $\mathrm{FK} \geq 1,50$. Hasilnya sebagai berikut

Tabel 2. Hasil Analisa Kestabilan Lereng Jalan Tambang Boboka.

\begin{tabular}{|c|c|c|c|c|c|c|}
\hline $\begin{array}{c}\text { Tinggi } \\
\text { Lereng } \\
\text { Tunggal } \\
\\
\text { (m) }\end{array}$ & $\begin{array}{c}\text { Sudut } \\
\text { Lereng } \\
\text { Tunggal }\end{array}$ & $\begin{array}{c}\text { Lebar } \\
\text { Berm } \\
(m)\end{array}$ & $\begin{array}{c}\begin{array}{c}\text { Tinggi } \\
\text { Keseluruhan } \\
\text { Lereng }\end{array} \\
\text { (m) }\end{array}$ & $\begin{array}{c}\text { Sudut } \\
\text { Keseluruhan } \\
\text { Lereng } \\
\\
(\text { deg })\end{array}$ & $\begin{array}{l}\text { Nilai } \\
\text { SRF }\end{array}$ & $\begin{array}{c}\begin{array}{c}\text { Probabilty } \\
\text { of Failure }\end{array} \\
\text { SRF } \leq 1,5 \\
(\%)\end{array}$ \\
\hline \multirow{4}{*}{20} & \multirow{4}{*}{60} & 3 & 40 & 57 & 1,51 & 49,08 \\
\hline & & \multirow{3}{*}{5} & 40 & 55 & 1,65 & 33,54 \\
\hline & & & 60 & 56 & 1,58 & 38,94 \\
\hline & & & 80 & 55 & 1,54 & 45,39 \\
\hline \multirow{4}{*}{30} & \multirow{4}{*}{55} & 3 & 60 & 53 & 1,37 & 66,86 \\
\hline & & 5 & 60 & 52 & 1,49 & 51,1 \\
\hline & & 8 & 60 & 50 & 1,58 & 36,27 \\
\hline & & & 90 & 49 & 1,52 & 47,74 \\
\hline
\end{tabular}

Keterangan :

$\mathrm{SRF} \geq 1,50$ dan $\mathrm{PF} \leq 50 \%:$ aman

$\mathrm{SRF} \leq 1,50$ dan $\mathrm{PF} \geq 50 \%$ : tidak aman

Berdasarkan hasil analisa diatas maka dipilih tinggi jenjang 20 meter, lebar berm 5 meter dan sudut lereng keseluruhan $55^{\circ}$ sebagai standar parameter desain jalan tambang Boboka yang baru.

\section{C.2. Desain lama dan desain baru jalan tambang Boboka}

Setelah mengetahui standar desain jalan tambang Boboka yang baru maka dibuatlah desain dan dilakukan perbandingan antara desain lama dan desain baru untuk mengetahui,

- Perbandingan moving material, kebutuhan unit alat berat dan kecepatan development

- Perbandingan dari Aspek QSCDME

- Efisiensi yang diperoleh

Perbandingan moving material, kebutuhan unit alat berat dan kecepatan development

Standar Lama (SP-09.100.503 R0)

Berikut Standar Parameter Geometri Lereng Jalan Tambang (SP-09.100.503 R0) PT Antam Tbk UBPN Maluku Utara 


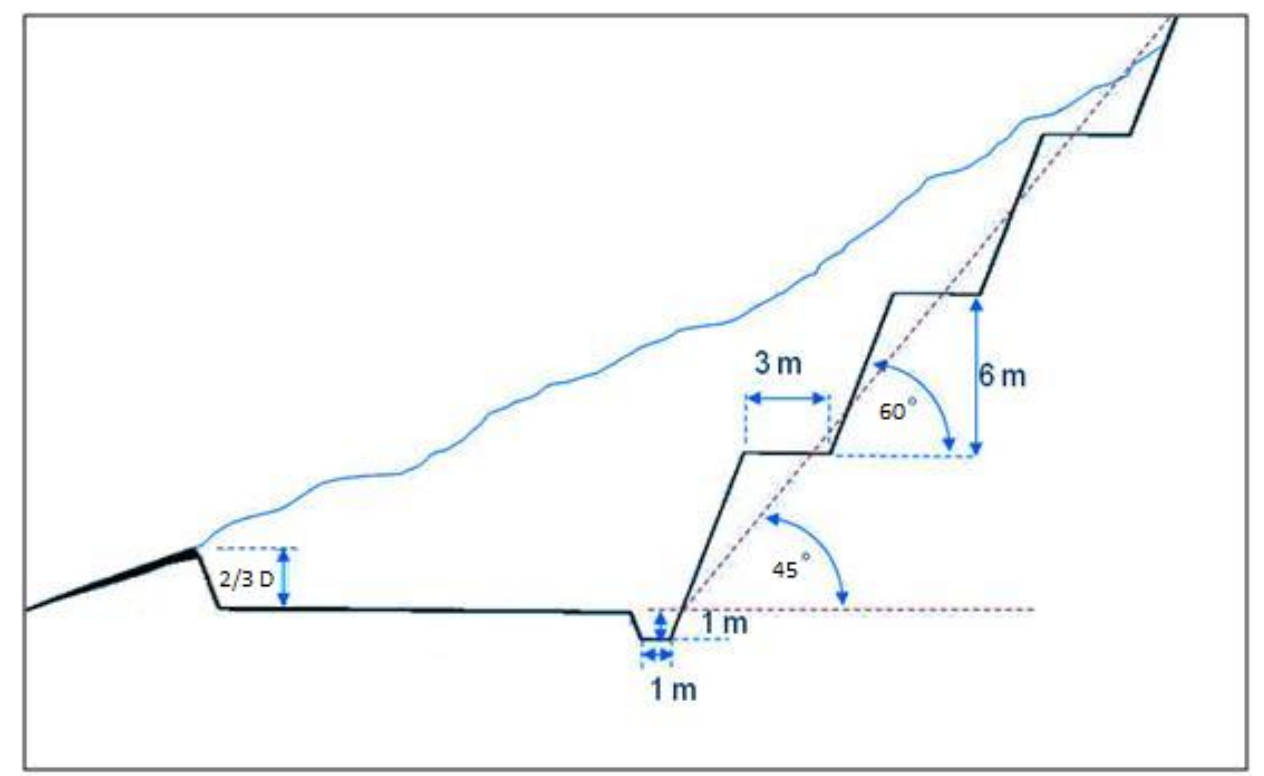

Gambar 2. Standar Parameter Geometri Lereng Jalan Tambang (SP-09.100.503 R0).

Dari Gambar 2, terlihat acuan Mine Plan PT Antam Tbk UBPN Maluku Utara dalam membuat desain geomter jalan. Sehingga dibuatlah desain berdasar standar parameter tersebut.

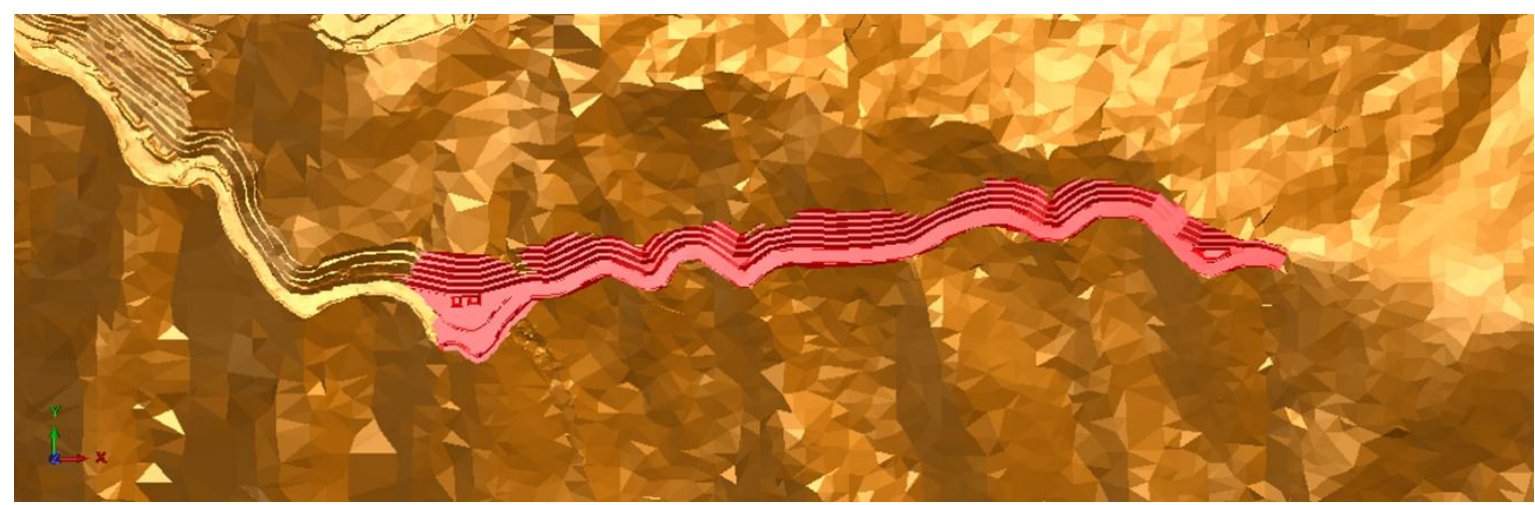

Gambar 3. Desain Jalan Tambang Boboka Berdasarkan SP-09.100.503 R0.

Dari desain jalan tambang Boboka yang mengunakan (SP-09.100.503 R0), didapatkan hasil sebagai berikut.

1. Estimasi material movement $\quad: 316.970 \mathrm{~m}^{3}$ atau 507.152 ton

2. Luas bukaan lahan baru $\quad: 61.715,94 \mathrm{~m}^{2}$ atau $6,2 \mathrm{Ha}$

3. Jarak target development $\quad: \pm 1.048 \mathrm{~m}$ atau $1,05 \mathrm{~km}$

Berdasarkan Rencana Kerja Anggaran Biaya (RKAB) UBP Nikel Malut 2018, diketahui bahwa biaya over burden removal sebesar $1 \mathrm{bcm}$ atau 1,6 ton adalah Rp. 30.703,00/ton. Sehingga biaya material movement desain lama jalan tambang Boboka adalah sebesar :

$$
\mathrm{B}_{\mathrm{MM}}=\mathrm{TM}_{\mathrm{d}} \cdot \mathrm{B}_{\mathrm{OB}}
$$

$$
\begin{array}{ll}
\mathrm{B}_{\mathrm{MM}} & =\text { Biaya material movement } \\
\mathrm{TM}_{\mathrm{d}} & =\text { Tonase total material movement desain } \\
\mathrm{B}_{\mathrm{OB}} & =\text { Biaya over burden removal } \\
& \\
\mathrm{B}_{\mathrm{MM}} & =507.152 \text { ton } \times \text { Rp. } 30.703,00 / \text { ton } \\
& =\text { Rp. } \mathbf{1 5 . 5 7 1 . 0 8 7 . 8 5 6 , 0 0}
\end{array}
$$


Selain itu, jika dilakukan perhitungan waktu penyelesaaiannya maka didapat hasil sebagai berikut,

Tabel 3. Estimasi Waktu Development Jalan Tambang Boboka Berdasarkan (SP-09.100.503 R0)

\begin{tabular}{lcc}
\hline \multicolumn{1}{c}{ Kebutuhan Alat } & \multicolumn{2}{c}{ Jalan Boboka } \\
\hline Articulated Dump Truck Volvo A40F & 8 & Unit \\
Excavator Volvo EC460BLc & 2 & Unit \\
Bulldozer Cat D8R & 2 & unit \\
Breaker Volvo EC330BLc & 1 & unit \\
Availability & 90 & $\%$ \\
Jarak ke wastedump & 2.958 & meter \\
Productivity & 63.394 & ton/bulan \\
Estimasi Waktu Penyelesaian & 8 & bulan \\
\hline
\end{tabular}

\section{Standar Baru (Hasil Kajian Geoteknik)}

Standar parameter yang dipilih dari hasil kajian geoteknik adalah sebagi berikut,

1. Tinggi jenjang : $20 \mathrm{~m}$

2. Lebar berm :5 m

3. Single slope $: 60^{\circ}$

4. Nilai $S R F \quad: 1,65$

Pemilihan standar ini dikarenakan nilai $S R F$ yang dimiliki paling tinggi. Dari standar ini kemudian dibuat desain jalan tambang Boboka

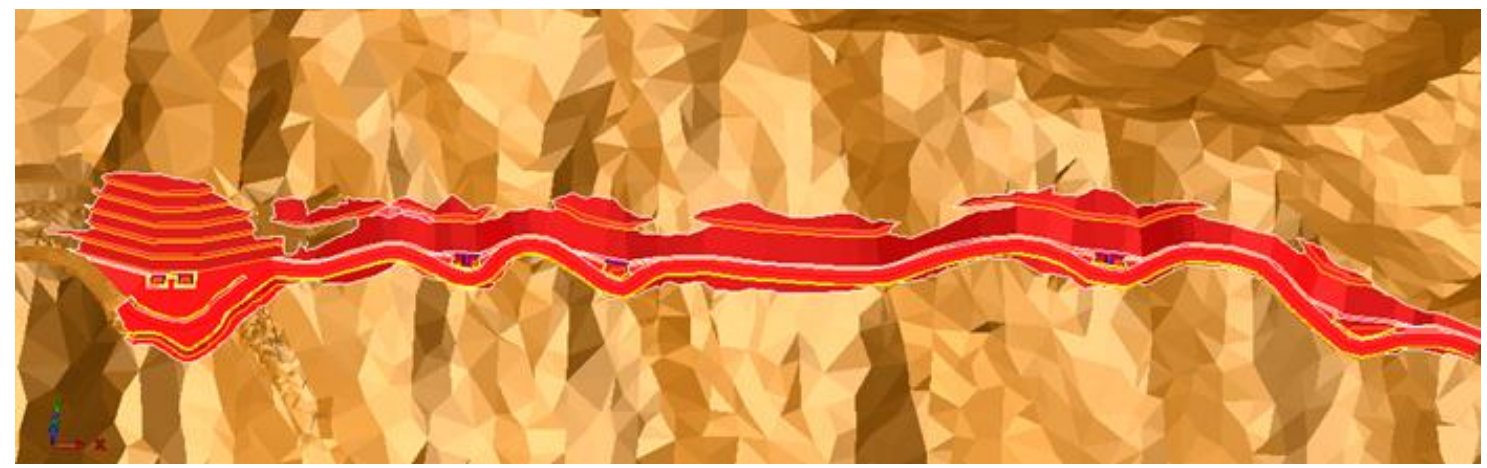

Gambar 4. Desain Jalan Tambang Boboka Berdasarkan Kajian Geoteknik.

Dari desain tersebut diperoleh hasil sebagai berikut

1. Estimasi material movement $\quad: 257.339 \mathrm{~m}^{3}$ atau 411.742 ton

2. Luas bukaan lahan baru $\quad: 50.817,98 \mathrm{~m}^{2}$ atau $5,1 \mathrm{Ha}$

3. Jarak target development $\quad: \pm 1.048 \mathrm{~m}$ atau $1,05 \mathrm{~km}$

Dari hasil material movement desain baru, dapat dihitung biaya material movement sebagai berikut

$$
\mathrm{B}_{\mathrm{MM}}=\mathrm{TM}_{\mathrm{d}} \cdot \mathrm{B}_{\mathrm{OB}}
$$

$\begin{array}{ll}\mathrm{B}_{\mathrm{MM}} & =\text { Biaya material movement } \\ \mathrm{TM}_{\mathrm{d}} & =\text { Tonase total material movement desain } \\ \mathrm{B}_{\mathrm{OB}} & =\text { Biaya over burden removal }\end{array}$

$\mathrm{B}_{\mathrm{MM}}=411.742$ ton $\times$ Rp. 30.703,00/ton

$=$ Rp. 12.641.714.626,00

Sedangkan waktu penyelesaaiannya adalah sebagai berikut, 
Tabel 4. Estimasi Waktu Development Jalan Tambang Boboka Berdasarkan Hasil Kajian Geoteknik.

\begin{tabular}{lcc}
\hline \multicolumn{1}{c}{ Kebutuhan Alat } & \multicolumn{2}{c}{ Jalan Boboka } \\
\hline Articulated Dump Truck Volvo A40F & 8 & unit \\
Excavator Volvo EC460BLc & 2 & unit \\
Bulldozer Cat D8R & 2 & unit \\
Breaker Volvo EC330BLc & 1 & unit \\
Availability & 90 & $\%$ \\
Jarak ke wastedump & 2.958 & meter \\
Productivity & 63.345 & ton/bulan \\
Estimasi Waktu Penyelesaian & 6,5 & bulan \\
\hline
\end{tabular}

\section{Perbandingan dari Aspek QSCDME}

Berikut perbandingan sebelum menggunakan kajian geoteknik dan sesudah menggunakan kajian geoteknik dari aspek quality, safety, cost, delivery, morale dan environment

Tabel 5. Perbandingan Aspek QCSDME.

\begin{tabular}{|c|c|c|}
\hline QSCDME & Sebelum & Sesudah \\
\hline Quality & $\begin{array}{l}\text { Material movement lebih banyak } \\
\text { Waktu development lebih lama }\end{array}$ & $\begin{array}{l}\text { Material movement berkurang secara } \\
\text { signifikan } \\
\text { Waktu development lebih cepat }\end{array}$ \\
\hline Safety & $\begin{array}{l}\text { Belum terdapat kajian geoteknik mengenai } \\
\text { kemantapan lereng }\end{array}$ & $\begin{array}{l}\text { Kajian geoteknik dilakukan serta } \\
\text { melakukan simulasi jika terjadi gempa } \\
\text { bumi }\end{array}$ \\
\hline Cost & $\begin{array}{l}\text { Biaya overburden removal besar karena } \\
\text { material movement yang banyak }\end{array}$ & $\begin{array}{l}\text { Dapat melakukan efisiensi karena materiat } \\
\text { movement yang berkurang }\end{array}$ \\
\hline Delivery & $\begin{array}{l}\text { Kegiatan produksi dapat terhambat karena } \\
\text { development jalan tambang terlambat }\end{array}$ & $\begin{array}{l}\text { Kegiatan produksi dapat lebih cepat } \\
\text { karena development jalan produksi lebih } \\
\text { cepat selesai }\end{array}$ \\
\hline Morale & $\begin{array}{l}\text { Keperccayaan diri operator kurang baik } \\
\text { karena belum adanya kajian geoteknik }\end{array}$ & $\begin{array}{l}\text { Motivasi tinggi karena sudah terdapat } \\
\text { kajian geoteknik }\end{array}$ \\
\hline Environment & Luas bukaan lahan besar & Luas bukaan lahan lebih kecil \\
\hline
\end{tabular}

\section{Efisiensi yang Diperoleh}

Efisiensi yang diperoleh dapat dihitung dengan cara meghitung selisih biaya material movement dari desain lama jalan tambang Boboka dan desain baru jalan tambang Boboka ditambah biaya kajian geoteknik. Sehingga dapat efisiensi dapat dirumuskan sebagai berikut

$$
\text { Efisiensi }(\mathrm{Rp})=\mathrm{BM}_{\mathrm{dl}}-\left(\mathrm{BM}_{\mathrm{db}}+\mathrm{BG}\right)
$$

$$
\begin{array}{ll}
\mathrm{BM}_{\mathrm{dl}} & =\text { Biaya material movement desain lama } \\
\mathrm{BM}_{\mathrm{db}} & =\text { Biaya material movement desain baru } \\
\mathrm{BG} & =\text { Biaya kajian geoteknik }
\end{array}
$$

Efisiensi $=$ Rp. 15.571.087.856,00 - (Rp. 12.641.714.626,00+ Rp. 150.000.000,00)

$$
=\text { Rp. 2.779.373.230,00 }
$$

Tabel 6. Perbandingan Biaya Material Movement Desain Lama dan Desain Baru.

\begin{tabular}{crr}
\hline $\begin{array}{c}\text { Desain Jalan Tambang } \\
\text { Boboka }\end{array}$ & $\begin{array}{c}\text { Total Material Movement } \\
\text { (ton) }\end{array}$ & Biaya (Rp) \\
\hline Desain Lama & 507.152 & $15.571 .087 .856,00$ \\
Desain Baru & 411.742 & $12.641 .714 .626,00$ \\
Selisih & 95.410 & $2.929 .373 .230,00$ \\
\hline
\end{tabular}


Tabel 7. Efisiensi.

\begin{tabular}{cr}
\hline Jenis Biaya & \multicolumn{1}{c}{ Biaya $(\mathbf{R p})$} \\
\hline Selisih Biaya Desain & $2.929 .373 .230,00$ \\
Biaya Geoteknik & $150.000 .000,00$ \\
Efisiensi & $2.779 .373 .230,00$ \\
\hline
\end{tabular}

\section{KESIMPULAN}

Berikut kesimpulan dari penilitian ini,

1. Dengan merubah standar desain jalan tambang yaitu tinggi jenjang dari 6 meter menjadi 20 meter, lebar berm dari 3 meter menjadi 5 meter dan sudut lereng keseluruhan dari $45^{\circ}$ menjadi $55^{\circ}$, nilai nilai Strength Reduction Factor $(S R F)$ sebagai representasi Faktor Keamanan (FK) jalan tambang Boboka naik dari 1,30 menjadi 1,65

2. Perubahan standar desain jalan tambang Boboka mengurangi jumlah material movement jalan tambang Boboka sebanyak 95.410 ton

3. Berkurangnya material movement berdampak pada semakin cepat dan efisiennya development jalan tambang Boboka

\section{DAFTAR PUSTAKA}

Dwinagara, Barlian. (2017): Kajian Geoteknik dan Hydrogeologi Development Jalan Boboka Site Tanjung Buli, Pusat Studi Mineral dan Energi Lembaga Penelitian dan Pengabdian kepada Masyarakat, Universitas Pembangunan Nasional "Veteran" Yogyakarta, 1 - 16.

Gemcom. (2011): Surpac Tutorial, Gemcom United State of America, 5 - 75.

Styawan, Anjas. (2017): Pemanfaatan "Road Center Line" untuk Mempercepat Proses Development Jalan Tambang, PT Antam Tbk, UBPN Maluku Utara, 1 - 13. 